\title{
Avaliação da predação de Podocnemis expansa e Podocnemis unifilis (Testudines, Podocnemididae) no rio Javaés, Tocantins
}

\begin{abstract}
Giovanni SALERA JUNIOR ${ }^{1}$, Adriana MALVASIO², Thiago Costa Gonçalves PORTELINHA ${ }^{3}$
RESUMO

Podocnemis expansa e P. unifilis são animais de vida longa, com uma demorada maturação sexual, o que influencia uma baixa taxa de substituição de indivíduos. Suas populaçōes são caracterizadas por uma pequena mortalidade dos animais adultos, mas alta taxa de mortalidade de filhotes e embriōes. Sendo a predação natural de ninhos e filhotes um dos fatores mais importantes do baixo sucesso de eclosão dessas espécies. No rio Javaés, os ovos e recém-eclodidos podem ser predados por uma grande diversidade de animais: dentre as aves, urubus (Coragyps atratus e Cathartes aura), carcará (Polyborus plancus), jaburu (Jabiru mycteria); lagartos (Tupinambis teguixin) e mamíferos de pequeno porte, coati (Nasua nasua) e cachorro-domato (Cerdocyon thous). Do total anual de desovas de P. unifilis em média 65,98\% são predadas, sendo 41,68\% de forma total e 24,30\% parcialmente. Enquanto que apenas 5,31\% das ninhadas de P. expansa são sempre parcialmente predadas. Dentre os predadores aquáticos existem diversos peixes, principalmente piranhas (Serrasalmus nattereri) e jacarés (Melanosuchus niger e Caimam crocodilus). Os predadores das fêmeas de P. unifilis são: jacaré-açu (Melanosuchus niger), onça-pintada (Panthera onca) e onça-parda (Puma concolor). Enquanto que as fêmeas de $P$. expansa em postura, somente são predadas por $P$. onca. As fêmeas de $P$. unifilis em postura são predadas num total médio de 3,93\% anualmente, enquanto que para $P$. expansa a média anual é $5,66 \%$ das fêmeas.
\end{abstract}

PALAVRAS-CHAVE: Podocnemis expansa, Podocnemis unifilis, predação, rio Javaés.

\section{Evaluation of predation in Podocnemis expansa and Podocnemis unifilis (Testudines, Podocnemididae) in the Javaés River, Tocantins}

\section{ABSTRACT}

Podocnemis expansa and $P$. unifilis long lived with late sexual maturation, which influences a low replacement rate of individuals. Their populations are characterized by low adults mortality, but high mortality of embryos and hatchlings. The natural nest predation is an important factor for hatchling success. In Javaés River, the eggs and hatchlings can be predated by a large number of animals such as birds, vultures (Coragyps atratus and Cathartes aura), carcará (Polyborus plancus), jabiru (Jabiru mycteria); lizards (Tupinambis teguixin) and small mammals, coati (Nasua nasua) and crab-eating-fox (Cerdocyon thous). About 65,98\% of nests of $P$. unifilis are predated (41,68\% totally and $24,30 \%$ partially). Only 5,31\% of $P$. expansa nests are partially predated. There are many aquatic predators, like carnivorous fish, mainly piranhas (Serrasalmus nattereri) and caimans (Melanosuchus niger e Caimam crocodilus). The predators of P. unifilis females are: black caiman (Melanosuchus niger), jaguar (Panthera onca) and puma (Puma concolor), and of $P$. expansa females is the $P$. onca. In average 3,93\% of $P$. unifilis females are predated annually while that to $P$. expansa the average is $5,66 \%$.

KEY WORDS: Podocnemis expansa, Podocnemis unifilis, predation, Javaés River.

\footnotetext{
1 Universidade Federal do Tocantins. E-mail: salerajunior@yahoo.com.br

2 Universidade Federal do Tocantins

${ }^{3}$ Universidade de São Paulo, Escola Superior de Agricultura "Luiz de Queiroz"
} 


\section{INTRODUÇÃO}

Podocnemis expansa (tartaruga-da-amazônia) e Podocnemis unifilis (tracajá) são os mais importantes representantes da fauna de quelônios da Amazônia, onde sua carne, vísceras e ovos servem de alimento para as comunidades locais e os seus cascos são utilizados como adorno e utensílios domésticos (Pritchard \& Trebbau 1984).

Assim como a maioria dos quelônios, P. expansa e P. unifilis são animais de vida longa, com uma demorada maturação sexual, o que influencia uma baixa taxa de substituição de indivíduos (Alfinito, 1973; Pritchard, 1979). Suas populações são caracterizadas por uma pequena mortalidade dos animais adultos, mas alta taxa de mortalidade de filhotes e embriōes (Ernst \& Barbour, 1989; IBAMA, 1989a; Soares, 2000), sendo a predação natural um dos fatores mais importantes do baixo sucesso de eclosão dessas espécies (Valle et al., 1973).

Segundo Pough et al. (1993) essas são características que predispõem uma espécie ao risco de extinção, quando condições variáveis aumentam a mortalidade de adultos ou reduzem drasticamente o recrutamento de jovens para a população.

Apesar de existirem inúmeras áreas onde essas espécies são protegidas e manejadas pelo RAN (Centro de Conservação e Manejo de Répteis e Anfíbios), órgão vinculado ao IBAMA (Instituto Brasileiro de Meio Ambiente e dos Recursos Naturais Renováveis), há uma escassez de estudos enfocando a predação natural de ninhos e animais adultos dessas populaçōes.

Este trabalho apresenta um levantamento da predação de ninhos, filhotes e exemplares adultos de P. expansa e P. unifilis, durante duas estações reprodutivas no rio Javaés, Tocantins.

\section{MATERIAL E MÉTODOS}

\section{ÁREA DE ESTUDO}

Esta pesquisa foi realizada na área do Projeto Quelônios da Amazônia, localizada entre os paralelos 9050' S e 1110' S e os meridianos 49056' W e 50³0' W, no rio Javaés, estado do Tocantins, região Norte do Brasil. A área é coordenada pelo RAN/ IBAMA e situa-se no entorno do Parque Nacional do Araguaia (Ilha do Bananal) e da Área de Proteção Ambiental Bananal/ Cantão (Figura 1).

O regime climático, segundo Köppen, é classificado como tropical úmido de transição (Aw) com duas estaçôes bem definidas: o verão (Novembro a Abril) meses em que predominam as chuvas, e o inverno (Maio a Outubro) onde marca-se o período da seca. O total pluviométrico anual fica em torno de $1.750 \mathrm{~mm}$, e a temperatura média anual gira em torno de $24^{\circ} \mathrm{C}$, mantendo-se praticamente constante ao longo de todo o ano (Ferreira Jr., 2003).
No período de menor vazão do rio Javaés, que ocorre geralmente no final de setembro, as praias apresentam bancos de areia com altitude média de 2,5 metros e as suas dimensões aproximadas correspondem a $700 \times 250$ metros para a menor praia e 4000 × 600 metros para a maior praia. Essas dimensōes podem variar anualmente, dependendo da vazão do rio e da deposição de areia nas praias.

\section{COLETA DE DADOS}

Dentre as 10 praias que integram a área do Projeto Quelônios da Amazônia, cinco praias da margem direita (Canguçu, Comprida, Coco, Goiaba e Bonita) foram monitoradas diariamente nos períodos da manhã e tarde, durante os meses de agosto a novembro em duas estaçóes reprodutivas (2002 e 2003) onde realizou-se o acompanhamento das predaçôes. As observaçôes foram realizadas entre $6 \mathrm{~h}-18 \mathrm{~h}$ em três turnos (Turno 1: 6h-10h; Turno 2: 10h01min- 14h; Turno 3: $14 \mathrm{~h} 01 \mathrm{~min}-18 \mathrm{~h}$ ) por dois membros da equipe de pesquisa portando binóculos à aproximadamente $50 \mathrm{~m}$ dos ninhos.

A identificação dos predadores se deu através da observação de rastros e pegadas deixadas nas praias e pela visualização direta, utilizando-se as seguintes obras: para mamíferos, Emmons \& Feer (1990) e Becker \& Dalponte (1999); para aves, Hidasi (1997) e para jacarés, CITES (1995).

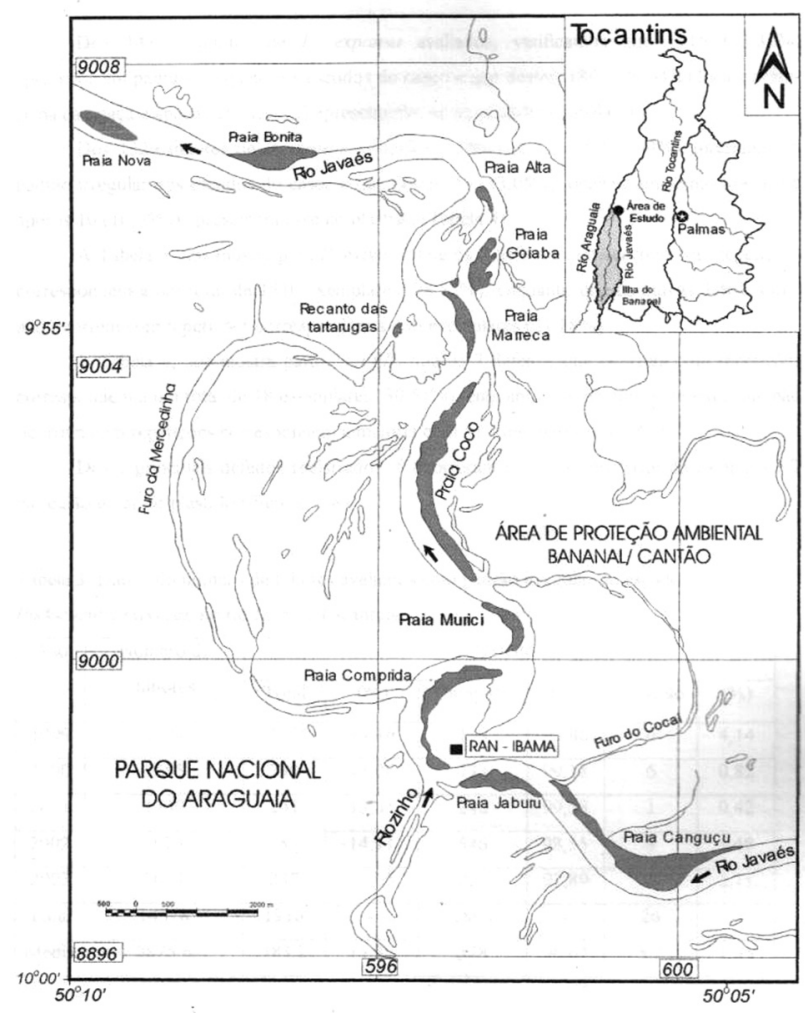

Figura 1 - Localização da área de estudo. 
Durante as atividades de soltura dos filhotes recémeclodidos realizou-se a observação da predação por peixes carnívoros, onde foram identificados através de Reis et al. (2003) após serem capturados com linha e anzol.

\section{RESULTADOS}

\section{PREDAÇÃO DE NINHOS}

Em P. unifilis, foram registradas 391 desovas nos dois anos de observação. Sendo que destas, 258 (65,98\%) foram predadas parcialmente ou de forma total, restando apenas $34,02 \%$ intactas (Tabela 1).

Para $P$. expansa, registramos 301 desovas e, destas, apenas $16(5,31 \%)$ foram parcialmente predadas (Tabela 2).

Nas praias do rio Javaés, os predadores mais ocorrentes dos ovos e filhotes de P. unifilis e P. expansa foram: urubu-decabeça-preta (Coragyps atratus), urubu-de-cabeça-vermelha (Cathartes aura), urubu-tinga (Cathartes burrovianus), carcarás (Polyborus plancus), gavião-carapateiro (Mivalgo chimachima), jaburu (Jabiru mycteria), cabeça-seca (Mycteria americana), maguari (Ciconia maguari) e garça-branca-grande (Casmerodius albus). Em menor escala aparecem, o lagarto teiú (Tupinambis teguixin), coati (Nasua nasua), cachorro-do-mato (Cerdocyon thous), garça-moura (Ardea cocoi), garça-brancapequena (Egretta thula) e socó-boi (Trigrisoma lineatum).

Como principal predador aquático, destacou-se a piranha vermelha (Serrasalmus nattereri) e em menor número as demais espécies desse gênero (Serrasalmus spp.).

Tabela 1 - Dados da predação de ninhos de Podocnemis unifilis, no rio Javaés, Tocantins.

\begin{tabular}{lcccc}
\hline \multirow{2}{*}{ Ano } & \multirow{2}{*}{ N $^{0}$ de } & \multicolumn{4}{c}{ Predação } \\
\cline { 3 - 5 } & desovas & Parcial (P) & Total (T) & P + T \\
\hline 2002 & 251 & $79(31,48 \%)$ & $126(50,19 \%)$ & $205(81,67 \%)$ \\
2003 & 140 & $16(11,42 \%)$ & $37(26,42 \%)$ & $53(37,84 \%)$ \\
\hline Total & 391 & $95(24,30 \%)$ & $163(41,68 \%)$ & $258(65,98 \%)$ \\
Média & 195,5 & 47,5 & 81,5 & 129 \\
\hline
\end{tabular}

Tabela 2 - Dados da predação de ninhos de Podocnemis expansa, no rio Javaés, Tocantins

\begin{tabular}{lll}
\hline Ano & $\mathrm{N}^{0}$ de desovas & Predação Parcial \\
\hline 2002 & 166 & $9(5,42 \%)$ \\
2003 & 135 & $7(5,18 \%)$ \\
Total & 301 & $16(5,31 \%)$ \\
Média & 150,5 & 8 \\
\hline
\end{tabular}

Os ninhos foram predados parcialmente por aves e, após sua inicial depredação, outros predadores, tais como lagartos e pequenos mamíferos também se aproximaram para consumir ovos e filhotes.

\section{PREDAÇÃO DE FÊMEAS EM POSTURA}

Após a saída do rio, as fêmeas de $P$. unifilis e $P$. expansa perambulam pelas praias escolhendo o local para desova, estando vulneráveis ao ataque de predadores, que podem ser carnívoros, Panthera onca (onça-pintada), Puma concolor (onça-parda) ou jacarés, Melanosuchus niger (jacaré-açu).

Durante a postura, as fêmeas de $P$. unifilis podem ser predadas por exemplares de $M$. niger, $P$. onca e $P$. concolor (Tabela 3), enquanto que as fêmeas de $P$. expansa foram predadas apenas por exemplares de $P$. onca (onça-pintada) (Tabela 4).

Para a correta relaçáo do percentual de fêmeas predadas, adotou-se a quantidade das fêmeas em posturas, que corresponde ao número total de ninhos, mais o número de fêmeas predadas antes de terem realizado a desova.

Das 13 fêmeas de $P$. expansa predadas em 2002, apenas uma foi morta quando retornava ao rio após ter realizado a desova. Todas as demais fêmeas de $P$. expansa e $P$. unifilis foram predadas antes da realização da desova.

Tabela 3 - Índice de fêmeas adultas de Podocnemis unifilis predadas durante estação de desova, no rio Javaés, Tocantins.

\begin{tabular}{cccccc}
\hline \multirow{2}{*}{ Ano } & \multirow{2}{*}{$\begin{array}{c}\text { Fêmeas em } \\
\text { postura }\end{array}$} & \multicolumn{5}{c}{ M. niger } & P. onca & P. concolor & Total \\
\cline { 3 - 6 } & & & M. predadas \\
\hline 2002 & 262 & $7(2,67 \%)$ & $3(1,14 \%)$ & $1(0,38 \%)$ & $11(4,20 \%)$ \\
\hline 2003 & 145 & $1(0,69 \%)$ & $2(1,38 \%)$ & $2(1,38 \%)$ & $5(3,49 \%)$ \\
Total & 407 & $8(1,96 \%)$ & $5(1,22 \%)$ & $3(0,73 \%)$ & $16(3,93 \%)$ \\
Média & 203,5 & 4 & 2,5 & 1,5 & 8 \\
\hline
\end{tabular}

Tabela 4 - Índice de fêmeas adultas de Podocnemis expansa predadas por Panthera onca durante estação de desova, no rio Javaés, Tocantins.

\begin{tabular}{lll}
\hline Ano & Fêmeas em postura & Fêmeas predadas \\
\hline 2002 & 178 & $13(7,30 \%)$ \\
2003 & 140 & $5(3,57 \%)$ \\
Total & 318 & $18(5,66 \%)$ \\
Média & 159 & 9 \\
\hline
\end{tabular}




\section{DISCUSSÃO}

\section{PREDAÇÃO DE OVOS E FILHOTES}

Os quelônios não exibem cuidado parental, de forma que os adultos não realizam a proteção das ninhadas e, além disso, o longo período de desenvolvimento embrionário torna os ninhos vulneráveis aos predadores (Pough et al., 1993). A maior ameaça natural para as populações de quelônios é a perda de seus ovos e filhotes pela predação (Ferri, 2002).

Um período extremamente crítico de atividade terrestre que ocorre na vida de todos os quelônios aquáticos, se dá durante a movimentação sobre o ambiente terrestre, quando os recém-eclodidos emergem dos ninhos e direcionam-se para a água. Podendo nesse momento ser atacados por inúmeros predadores (Gibbons, 1970). Nas praias do rio Javaés, observou-se que durante o percurso até a água, os filhotes recém-eclodidos são atacados predominantemente por aves do gênero Coragyps e da espécie Polyborus plancus que realizam suas estratégias de caça individualmente, através de ataques aéreos, ou em grupos, cercando os filhotes próximos aos ninhos. Além disso, foi observado que as aves maiores, como as espécies Jabiru mycteria e Mycteria americana, tragam os filhotes inteiros e as aves menores, como Coragyps atratus, estripam-nos profundamente, deixando somente o frágil casco descarnado na areia.

Segundo Swingland \& Stubbs (1985), a vulnerabilidade dos ninhos à predação, o sucesso da eclosão e o sexo dos recém-eclodidos são todos dependentes da seleção do local de desova. Diversos fatores podem influenciar a taxa de predação, dentre os quais, o ambiente de nidificação, a disponibilidade de predadores e as características e a densidade das covas (Burger, 1976; Burke et al., 1998; Pezzuti \& Vogt, 1999; Ferreira Jr., 2003).

Os ninhos de $P$. unifilis são mais rasos $(20 \mathrm{~cm}$ de profundidade) do que os de $P$. expansa ( $80 \mathrm{~cm}$ de profundidade) (IBAMA, 1989b). Neste estudo, quase 70\% dos ninhos de $P$. unifilis foram predados, enquanto que para $P$. expansa este valor foi de aproximadamente $5 \%$. Estes resultados sugerem que a profundidade da cova pode ser uma variável essencial sobre os índices de predação.

Iverson (1991a), em trabalho realizado com Kinosternon flavescens (quelônio de água doce), identificou que a mortalidade durante o primeiro ano de vida foi extremamente alta $(81,0 \%)$, em razão principalmente da predação e inviabilidade dos ovos. Dentre os quelônios do rio Javaés, esta característica foi observada para $P$. unifilis onde uma alta taxa de mortalidade $(65,98 \%)$ pode ocorrer na primeira fase de vida em função da predação de ovos e filhotes, contrapondo um pequeno percentual para os animais adultos (aproximadamente $4 \%$ ), assim como foi observado para outras espécies de quelônios amazônicos (Roze, 1964; Alho, 1985; Iverson, 1991b; IBAMA, 1989b; Soares, 2000)

Concernente ao alto índice de predação de ninhos de $P$. unifilis e $P$. expansa, outros autores corroboram, dentre os quais, Pritchard \& Trebbau (1984) e Soini (1995), afirmando que durante o período de desova, grande número de pássaros predadores permanecem nas praias para predar os ovos de covas de postura recente ou, ainda, ovos que tenham sido removidos por uma tartaruga fêmea desovando em um local próximo a outra cova. Dentre esses incluem urubus (Coragyps atratus e Cathartes aura), carcarás (Polyborus plancus), gaviōes (Mivalgo chimango) e jaburus (Jabiru mycteria e Mycteria americana). E depois, no fim da estação de desova, os mesmos predadores ficam à espera dos recém-eclodidos. Tais predadores têm sido registrados na área de estudo, nos períodos de desova e eclosão das ninhadas desses quelônios.

Os ninhos de $P$. expansa que possuem de 40 a 160 ovos (média 100) (IBAMA, 1989b) podem ainda ser infestados por grilos (Grillotelpidae) e larvas de moscas (Sarcophagidae) que parasitam e predam os ovos durante a incubação (Hidelbrand et al., 1997). O número de ovos por postura em $P$. unifilis é relativamente menor, de 8 a 32 ovos (média de 20) e podem ser invadidos por formigas (Formicidae) (IBAMA, 1989a; 1989b). A ocorrência de larvas de moscas foi observada principalmente em ovos de $P$. expansa contribuindo para a mortalidade dos embrióes, entretanto não foi constatada a presença de grilos e/ou formigas nos ninhos de ambas as espécies.

Segundo Ojasti (1967, 1971), no rio Orinoco (Venezuela), a perda de filhotes recém-eclodidos de $P$. expansa logo que emergem dos ninhos fica em torno de 5,9\%, e ainda enfatiza que inúmeros peixes que se concentram nas cercanias das praias aumentam significativamente essa perda. $\mathrm{O}$ autor enfatiza ainda que a mortalidade natural de adultos é baixa e quando ocorre se deve principalmente a acidentes, tais como: assoreamento dos cursos d'água e depredação do seu habitat

Os filhotes e juvenis de $P$. expansa e $P$. unifilis, nos cursos d'água são predados por anuros, sapos (Buffo sp.), por jacarés (Paleosuchus spp., Caiman crocodilus) e diversos peixes carnívoros, dentre os quais, bagres (Pimelodidae), piranhas (Serrasalmus sp., Pygocentrus sp. e Pygopristis sp.), pirararas (Phractocephalus hemiliopterus), aruanãs (Osteoglossum bicirrhosum), piraíbas (Brachyplatistoma filamentosum), jaus (Paulicea luetkeni) (Medem, 1969; IBAMA, 1989b; Hidelbrand et al., 1997). A predação por anfíbios anuros e jacarés não foi constatada para os filhotes das espécies estudadas, sendo as piranhas do gênero Serrasalmus os únicos predadores aquáticos identificados.

No presente estudo, os ovos e filhotes podem ainda ser atacados por lagartos teiús (Tupinambis teguixin), coati (Nasua nasua) e cachorro-do-mato (Cerdocyon thous), assim como também foi observado por Escalona \& Fá (1998). Tupinambis 
teguixin são os maiores predadores das covas de $P$. unifilis, $P$. sextuberculata e P. expansa no Peru (Soini, 1995) e na Venezuela (Escalona \& Fá, 1998)

Outros animais são conhecidos predadores de quelônios. Exemplares de Procyon cancrivorus (mão-pelada), Conepatus chinga (zorrilho ou cangambá) e Cerdocyon thous (cachorrodo-mato) predam ovos e filhotes de Trachemys dorbignyi (tigre d'água) no Sul do Brasil (Krause et al., 1982; Santos \& Hartz, 1999). Ratos escavam os ninhos de quelônios e consomem seus ovos durante o período de incubação, porcos domésticos predam os filhotes pequenos e, em muitas localidades, cabras e burros competem com os jabutis pelo alimento vegetal (Storer et al., 1989). Nas proximidades da área de estudo não se tem verificado a presença de animais domésticos que poderiam estar contribuindo para o aumento das taxas de mortalidade dessas espécies.

Diferentemente do que foi observado para $P$. expansa e P. unifilis, algumas espécies de quelônios apresentam poucos predadores. Segundo Swingland \& Stubbs (1985) os jabutis gigantes (Geochelone gigantea e Geochelone elefhantopus) possuem apenas um predador de ninhos, um grande caranguejo terrestre (Birgus latro).

Diversos trabalhos recomendam a transferência de covas ameaçadas de predação ou perdas por causas naturais (Wyneken et al., 1988; IBAMA, 1989a; Páez \& Bock, 1998). Entretanto, inúmeros estudos enfatizam que os projetos envolvendo o manejo de covas de quelônios devem considerar as particularidades do local de origem, dos locais de transferência e da idade do embrião. Devendo buscar, sempre que possível, áreas com características sedimentológicas similares ao local de origem dos ninhos (Spotila \& Standora, 1986; IBAMA, 1989b; Souza, 1992; Ferreira Jr., 2003) e o tempo de incubação com menor influência sobre a mortalidade de embriōes (Bonach et al., 2003).

Limpus \& Miller (1980) recomendam que em locais de severa predação dos ovos de quelônios, todo esforço deve ser empregado no controle do predador, quer seja pela exclusão ou pela remoção, ao invés de escolher a mais barata e provavelmente a mais desastrosa ação de manusear e transplantar os ovos para outros locais. No rio Javaés, o controle e a remoção de predadores mostram-se como uma alternativa inviável tendo em vista a amplitude da área de desova, que engloba um grande número de praias de grande extensão, e também pela enorme diversidade de predadores. Uma alternativa viável para a redução da predação seria o uso de armaçōes de ferro recobertas por telas metálicas, onde já demonstraram grande eficiência em trabalhos de conservação de algumas espécies de quelônios.

Segundo Swingland \& Stubbs (1985), a perda de ovos através da predação é menos devastadora em longo prazo, do que a perda através da colocação do ninho em um local inapropriado, tanto em termos de temperaturas muito altas ou muito baixas para a incubação ocorrer adequadamente, ou em termos da razão sexual.

Tendo em vista que em diversas áreas onde o IBAMA coordena atividades de manejo e proteção dessas espécies, os ovos são transferidos para outras localidades com a finalidade de evitar a predação e a inundação das covas, pela subida repentina do nível d'água dos rios (Cantarelli, 1997; Malvasio, 2001), trabalhos que apontem as implicaçôes da transferência de ninhos devem ser realizados para se poder subsidiar de forma adequada às atividades de manejo de ovos. Aspectos relacionados ao sucesso de eclosão e aqueles que enfocam a influência do ambiente de nidificação sobre a razão sexual das ninhadas devem ser priorizados.

\section{PREDAÇÃO DE FÊMEAS EM POSTURA}

Os quelônios adultos possuem menos inimigos naturais do que os filhotes e juvenis: a presença do resistente casco ósseo é um obstáculo suficiente para minimizar as taxas de predação dos adultos (Ferri, 2002).

Soares (2000) em trabalho realizado no rio Guaporé, estado de Rondônia, durante 10 anos (1989 a 1998), apresentou que a mortalidade das fêmeas adultas de $P$. expansa é praticamente nula naquela área. Sendo apenas preocupantes os índices de caça, exercida pela comunidade ribeirinha que ameaçam a estabilidade daquela população de quelônios, tornando ineficientes os resultados do Projeto de Conservação coordenado pelo IBAMA que é desenvolvido naquela localidade.

A predação de quelônios adultos por onças (P. concolor e $P$. onca) já foi observada em diversos estudos na Amazônia brasileira e colombiana para as espécies Geochelone carbonaria, Geochelone denticulata, P. expansa e P. unifilis (Humboldt, 1852; Goeldi, 1906; Medem, 1969; Hidelbrand et al., 1997). Os resultados obtidos neste estudo corroboram com as informações citadas anteriormente, tendo em vista que fêmeas em postura de $P$. expansa do rio Javaés são predadas exclusivamente por $P$. onca, podendo ocorrer também em menor proporção para a espécie $P$. unifilis.

Os pequenos exemplares de $P$. vogli podem ser predados por jacarés $(C$. crocodilus) e os grandes por crocodilos (Crocodylus intermedius), sucuris (Eunectes murinus) e onças (P. onca) (Ramo, 1980 appud Pritchard \& Trebbau, 1984). No presente estudo, a predação por jacarés foi registrada somente para a espécie $P$. unifilis, o que possivelmente pode estar relacionado ao tamanho dos exemplares, onde indivíduos adultos dessa espécie apresentam características morfológicas semelhantes à espécie $P$. vogli e são menores que indivíduos da espécie $P$. expansa.

Emmons (1989) em coleta de dados realizada na Estação Biológica de Cocha Cashu, Parque Nacional Manu (Peru) e 
na região do rio Arataye (Guiana Francesa) apresentou dados da predação de exemplares de Geochelone denticulata (jabuti), P. unifilis (tracajá) e Platemys platycephala (cágado) por P. onca. A autora descreve que esses quelônios têm o casco quebrado, geralmente na porção superior da carapaça, por onde o animal retira e consome seu conteúdo (carne e vísceras).

P. expansa é o maior quelônio de água doce encontrado na América do Sul. As fêmeas quando adultas atingem cerca de 80 $\mathrm{cm}$ (comprimento da carapaça) e pesam até $60 \mathrm{~kg}$ (IBAMA, 1989b). Já as fêmeas de $P$. unifilis são menores, medindo cerca de $38 \mathrm{~cm}$ e pesando em torno de $8 \mathrm{~kg}$ (IBAMA, 1989a). Os dados obtidos demonstraram que fêmeas adultas de $P$. unifilis apresentam um maior número de predadores que $P$. expansa, isso pode ser atribuído, possivelmente, ao seu menor porte e massa corpórea.

Os conhecimentos ligados às taxas de predação de fêmeas em postura podem subsidiar uma melhor compreensão da estrutura dessas populaçōes, pois tais predaçōes podem estar favorecendo a uma maior proporção de machos nessa localidade.

\section{AGRADECIMENTOS}

Este trabalho só foi possível com o apoio recebido pelo NATURATINS, através de Isac Braz da Cunha, Adriana Cavenage e Marcos Aurélio Rodrigues Jorge. $\mathrm{O}$ apoio às etapas de campo foi dado pelo RAN/IBAMA, pelo Instituto Ecológica e Earthwatch Institute. Nós gostaríamos de agradecer a Divaldo Rezende, Stephano Merlim, Mariluce Messias e Maria Tereza do Instituto Ecológica e Antônia Lúcia Mendes do Carmo, Yeda de Lucena Bataus e Selma Cristina do RAN/IBAMA. A coleta de dados somente foi possível com a ajuda dos agentes de praia do RAN/ IBAMA, Alfreu, Luciene, Kennedy e Pompeu, e alunos da Universidade Federal do Tocantins, Eliene, Marcos, Adson, Angélica, Glennya, Graciele, Darlei, Caroline, Larissa, Bárbara e Shislena. Agradecemos aos professores da Universidade Federal do Tocantins, Paulo Dias Ferreira Júnior e Lilyan Luizaga, da Universidade de São Paulo, Ana Maria de Souza e Érika Schlenz pela ajuda prestada. Agradecemos também aos voluntários do Earthwatch Institute que participaram ativamente da coleta de dados.

\section{BIBLIOGRAFIA CITADA}

Alfinito, J. 1973. Fundamentos ao serviço de proteção à tartaruga. Preservação da tartaruga da Amazônia. Ministério da Agricultura. DEMA/ PA, IBDF, Belém (PA), p. 1-36.

Alho, C.J.R. 1985. Conservation and management strategies for commonly exploited Amazonian turtles. Biol. Conserv., 32: 291-298
Becker, M. \& Dalponte, J.C. 1999. Rastros de mamiferos silvestres brasileiros: um guia de campo. $2^{\mathrm{a}}$ ed., Brasília; Ed. UnB; Ed. IBAMA. 180 pp.

Bonach, K.; Miranda-Vilela, M.P.; Alves, M.C. \& Verdade, L.M. 2003. Effect of translocation on egg viability of the giant Amazon river turtle (Podocnemis expansa). Chelonian Conservation Biology 4(3):712-715.

Burger, J. 1976. Temperature relationships in nests of the northern diamondback terrapin, Malclemys terrapin terrapin. Herpetologica, 32(4): 412-418.

Burke, V.J.; Rathbun, S.L.; Bodie, J.R. \& Gibbons, J.W. 1998. Effects of density on predation rate for turtle nests in a complex landscape. Oikos, 83 (1): 3-11.

Cantarelli, V.H. 1997. The Amazon turtles - Conservation and management in Brazil. In: Van Abbema, J. (Ed) Proccedings: Conservation, Restoration, and Management of Tortoises and Turtles - An International Conference. New York: New York Turtle and Tortoise Society. p. 407-410.

CITES, 1995. CITES Identification Guide-Crocodilians. Minister of Suplly and Services Canada. Canada.

Emmons, L.H. 1989. Jaguar predation on Chelonians. Journal of Herpetology, 23 (3): 311-314.

Emmons, L.H. \& Feer, F. 1990. Neotropical Rainforest Mammals: A Field Guide. The University of Chicago Press, Chicago.

Escalona, T. \& Fá, J.E. 1998. Survival of nests of the terecay turtle (Podocnemis unifilis) in the Nichare-Tawadu Rivers, Venezuela. Journal of Zoology, 244: 303-312.

Ernst, C.H. \& Barbour, R.W. 1989. Turtles of the World. Washington, Smithsonian Institution Press. 313 pp.

Ferreira Jr., P.D. 2003. Influência dos processos sedimentológicos e geomorfológicos na escolha das áreas de nidificação de Podocnemis expansa (tartaruga-da-amazônia) e Podocnemis unifilis (tracajá), na bacia do rio Araguaia. Ouro Preto, Universidade Federal de Ouro Preto. (Tese de Doutorado em Ciências Naturais, Universidade Federal de Ouro Preto). 296 pp.

Ferri, V. 2002. Turtles \& Tortoises: A Firefly Guide. Firefly Books. $256 \mathrm{pp}$.

Gibbons, J.W. 1970. Terrestrial activity and the population dynamics of aquatic turtles. The American Midland Naturalist, 83 (2): 404-414.

Goeldi, E.A. 1906. Chelonios do Brazil. Boletim do Museu Goeldi, Pará-Brasil, 4 (1-4): 699-756.

Hidasi, J. 1997. Aves de Goiânia. Goiânia: Fundação Jaime Câmara. $324 \mathrm{pp}$.

Hildebrand, Von P.; Bermudéz, N. \& Peñuela, M.C.M. 1997. La tortuga charapa (Podocnemis expansa) en el bajo rio Caqueta, Amazonas, Colombia. Aspectos de la biología reproductiva y técnicas para su manejo. Disloque Editores Ltda., Santafé de Bogotá, 152 pp.

Humboldt, A.Von. 1852. A personal narrative of travels to the equinoctal regions of America during 1799-1804. Vol. 2 H.G.Bohn, London, 521 pp. 
IBAMA - Instituto Brasileiro do Meio Ambiente e dos Recursos Naturais Renováveis. 1989a. Projeto Quelônios da Amazônia - 10 anos. IBAMA. Brasília, 119 pp.

IBAMA - Instituto Brasileiro do Meio Ambiente e dos Recursos Naturais Renováveis. 1989b. Projeto Quelônios da Amazônia: Manual Técnico. IBAMA. Brasília, 125 pp.

Iverson, J.B. 1991a. Life history and demography of the yellow mud turtle, Kinosternon flavescens. Herpetologica, 47 (4): 373-395.

Iverson, J.B. 1991b. Patterns of survivorship in turtles (order Testudines). Canadian Journal Zoology, 69: 385-391.

Krause, L.; Gomes, N. \& Leyser, K.I. 1982. Observações sobre a nidificação e desenvolvimento de Chrysemys dorbigni (Dumeril \& Bibron, 1835) (Testudines, Emididae) na Estação Ecológica do Taim, Rio Grande do Sul. Revista Brasileira de Zoologia, São Paulo (SP), 4 (1): 79-90.

Limpus, C.J. \& Miller, J.D. 1980. Potencial problems in artificial incubation of turtle eggs. Herpetological Review, 12 (1): 23-24.

Malvasio, A. 2001. Aspectos do mecanismo alimentar e da biologia reprodutiva em Podocnemis expansa (Schweigger,1812), Podocnemis unifilis (Troschel,1848) e P. sextuberculata (Cornalia, 1849) (Testudines, Pelomedusidae). São Paulo, Universidade de São Paulo (Tese de doutorado em Zoologia, Instituto de Biociências da Universidade de São Paulo). 199 pp.

Medem, F. 1969. Estudios adicionales sobre los Crocodylia y e Testudinata del Alto Caquetá y río Caguán. Caldasia, 10 (48): 329-353

Ojasti, J. 1967. Consideraciones sobre la ecologia y conservación de la tortuga Podocnemis expansa (Chelonia, Pelomedusidae). Atas Simpósio Biota Amazônica, 7: 201-206.

Ojasti, J. 1971. La tortuga arrau del Orinoco. Defensa de la Natureleza, Venezuela, 1 (2): 3-9.

Páez, V.P \& Bock, B.C. 1998. Temperature effect on incubation period in the yellow-spotted river turtle, Podocnemis unifilis, in the Colombian Amazon. Chelonian Conservation and Biology, 3 (1): 31-36.

Pezzuti, J.C.B. \& Vogt, R.C. 1999. Nesting ecology of Podocnemis sextuberculata (Testudines, Pelomedusidae) in the Japurá river, Amazonas, Brazil. Chelonian Conservation and Biology, 3 (3): 419-424.

Pough, F.H.; Heiser, J.B. \& McFarland, W.N. 1993. A Vida dos Vertebrados. Atheneu Editora. São Paulo (SP), 839 pp.

Pritchard, P.C.H. 1979. Encyclopedia of Turtles. T.F.H. Publ. Inc., Neptune, New Jersey. 859 pp.
Pritchard, P.C.H. \& Trebbau, P.1984. The Turtles of Venezuela. S.1p. Society for the Study of Amphibians and Reptiles. 403 pp.

Reis, R.E. et al. (org.). 2003. Check List of the Freshwater Fishes of South and Central America, 729 p., EDIPUCRS.

Roze, J.A. 1964. Pilgrim of the River. Nat. Hist., 73 (7): 35-41.

Santos, M.F.M. \& Hartz, S.M. 1999. The food habits of Procyon cancrivorus (Carnivora, Procyonidae) in the Lami Biological Reserve, Porto Alegre, Southern Brazil. Mammalia, 63 (4): 525-530.

Soares, M.F.G.S. 2000. Distribuição, mortalidade e caça de Podocnemis expansa (Testudines: Pelomedusidae) no rio Guaporé. Manaus, Instituto Nacional de Pesquisa da Amazônia - INPA (Dissertação de Mestrado em Ecologia - INPA). 54 pp.

Soini, P. 1995. Investigaciones en la Estación Biológica Cahuana. Reporte Pacaya-Samiria, Universidad Nacional Agraria la Molina. 425 pp.

Souza, R.R. 1992. Fatores que influenciam a determinação de sexo no tracajá (Podocnemis unifilis, Testudinata: Pelomedusidae). Manaus, Instituto Nacional de Pesquisa da Amazônia - INPA (Dissertação de Mestrado - Instituto Nacional de Pesquisas da Amazônia - INPA). 49 pp.

Spotila, J.R. \& Standora, E.A. 1986. Sex determination in the desert tortoise: a conservative management strategy is needed. Herpetologica, 42 (1): 67-72.

Storer, T.I.; Usinger, R.L.; Stebbins, R.C. \& Nybakken, J.W. 1989. Zoologia Geral. Sexta Edição Revista e Aumentada (Segunda Reimpressão). Companhia Editora Nacional. 816 pp.

Swingland, I.R. \& Stubbs, D. 1985. The ecology of mediterranean tortoise (Testudo hermanii). Reproduction Journal Zoology, 205: 595-610.

Valle, R.C.; Alfinito, J. \& Silva, M.M.F. 1973. Contribuição ao estudo da tartaruga amazônica. Preservação da tartaruga da Amazônia. Ministério da Agricultura. DEMA/ PA, IBDF, Belém (PA), p. 66-88.

Wyneken, J.; Burke, J.; Slamon, M. \& Pedersen, K., 1988. Egg failure in natural and relocated sea turtle nests. Journal of Herpetology, 22 (1): 88-96.

Recebido em 27/11/07

Aceito em 26/10/08 
